\title{
JCNaR
}

\section{Fabrication of Complex Polyelectrolyte Membrane of Chitosan-Pectin Crosslinked as Bioadsorbent}

\author{
Friska Septiani Silitonga ${ }^{1}$, Dwi Siswanta ${ }^{2}$, Mudasir $^{3}$ \\ ${ }^{1}$ Universitas Maritim Raja Ali Haji, Jl.Politeknik Senggarang, 29100, Tanjungpinang, Indonesia \\ ${ }^{2}$ Universitas Gadjah Mada, Sekip Utara, Bulaksumu, 55281, Yogyakarta, Indonesia \\ ${ }^{3}$ Universitas Gadjah Mada, Sekip Utara, Bulaksumu, 55281, Yogyakarta, \\ Indonesia
}

\begin{abstract}
Biopolymers are polymers fabricated from natural polymers which are biodegradable, non-toxic and renewable. This research was aimed to synthesize and characterize biopolymer made from chitosan and pectin and was made to be a membrane cross-linked with glutaraldehyde and then characterized. The chitosan-pectin crosslinked glutaraldehyde polyelectrolite complex (PEC) and membrane can be used as a bioadsorbent for metal and cationic dyes. Firstly, PEC membrane chitosan-pectin crosslinked glutaraldehyde was synthesized by dissolving chitosan in acetic acid and pectin in distilled water and added with glutaraldehyde as a crosslinked agent, then heated at $70{ }^{\circ} \mathrm{C}$. The amount of $1 \mathrm{M} \mathrm{NaOH}$ solution was added for 12 hours and then cleaned with distilled water and dried at room temperature. Subsequently, the membrane was characterized with FTIR spectrophotometer, medium acidity test, and water uptake. The results of the characterization of PEC mebmbrane chitosan-pectin crosslinked glutaraldehyde with FTIR showed the interaction between $-\mathrm{NH}_{3}{ }^{+}$of chitosan with $-\mathrm{COO}^{-}$group of pectin at a wavelength of $1604.77 \mathrm{~cm}^{-1}$. The medium acidity test showed that the PEC membrane chitosan-pectin crosslinked with glutaraldehyde was stable at $\mathrm{pH}$ 3-9 with water absorption of $266.67 \%$, with the composition of chitosan-pectine membrane of $70: 30$ with $30 \%$ glutaraldehyde.
\end{abstract}

Keyword: medium acidity, PEC membrane crosslinked, water uptake

Received 30 July 2019 | Revised 26 August 2019 | Accepted 29 August 2019

\section{Introduction}

The synthetic process of polymers is dealing with expensive costs, which is caused by the materials used are relatively expensive and must be imported. Therefore, an effort is needed to synthesize polymers by utilizing materials sourced from natural or renewable materials from natural resources in Indonesia. One of the ingredients that can be used as a base for biopolymers is chitosan (Herwanto, 2006). Chitin is a polysaccharide that forming the outer skeleton of a

\footnotetext{
*Corresponding author at: Universitas Maritim Raja Ali Haji, Jl.Politeknik Senggarang, 29100, Tanjungpinang, Indonesia

E-mail address: friska.septiani89@umrah.ac.id
} 
crab. Chitin is a polymer that can be degraded by microorganisms. Due to the natural origin of chitin, different variants are found in environment. In addition, when chitin is submitted to different chemical processes, a series of polymers varying in the degree of deacetylation (DD), molecular weight (MW), viscosity, pKa, etc, may be generated (Chatelet, 2000; Canella, 2001; Singla et al , 2001). Chitin can be isolated into chitosan by deacetylation process by removing the acetyl group. Chitosan is a biopolymer that is biodegradable and non-toxic (Gargioni, et.al, 2006). The deacetylation degree (DD) of chitosan and its derivative was determined by infrared spectroscopy (Bomem MB-100 FTIR, Germany) and ninhydrin titration The substitution degree (SD) was determined using the same techniques. (Curroto et al, 1999; Canella et al , 2001; Khan et al , 2002, Dee et al, 2001). Chitin is a polysaccharide that forming the outer skeleton of a crab. Chitin is a polymer that can be degraded by microorganisms. Chitin can be isolated into chitosan by deacetylation process by removing the acetyl group. Chitosan is a biopolymer that is biodegradable and non-toxic (Tanasale, et.al, 2012). Chitosan is poly [ $\beta$ $(1,4)$-2-amino-2-deoxy-D-glucopiranose] (Marudova, et.al 2004). Chitosan which has hydroxyl $(-\mathrm{OH})$ and amine groups (-NH2) thus results in effective chitosan to become adsorbent of cations from metals and cationic dyes (Rahmawati \& Iskandar, 2014). In an acidic condition, the $-\mathrm{NH} 2$ the functional group will be protonated to $-\mathrm{NH} 3+$ and make chitosan to be a cationic polysaccharide.

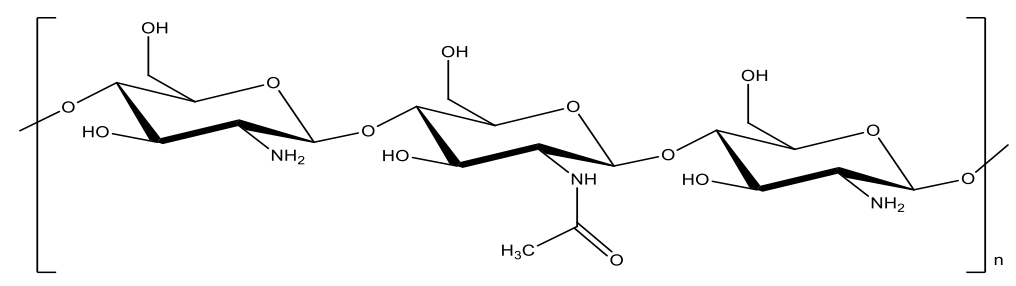

Figure 1. Chitosan Stucture

The modifications to increase the ability of chitosan can be performed by fabricating composites with other polymers, both natural and synthetic polymers. Natural polymers that can be used to process composites with chitosan are namely pectin. Pectin is a polysaccharide that contains $\alpha$ D-galacturonate residues which are linked by $\alpha-1.4$ glycosidic bonds (Ma, et.al, 2011). The carboxylic group (-COOH) found in the pectin makes the pectin as an anion polysaccharide or polyanion. In addition, pectin also has hydroxyl and methoxy functional groups.

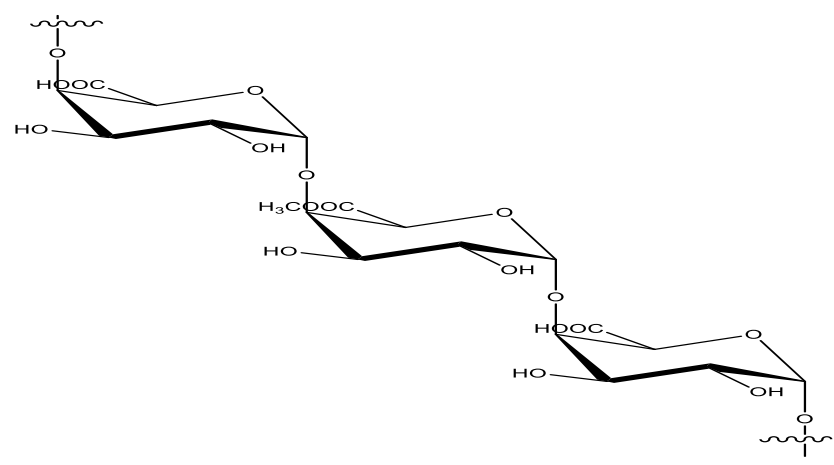


Figure 2. Pectin Structure

For the existence of the -NH3+ group from chitosan and carboxyl (-COO-) from pectin, there can be an interaction between polycation and polyanion to form complex polyelectrolytes. The purpose of adding glutaraldehyde is as a crosslinking agent so that the membrane structure can be stable at very acidic $\mathrm{pH}$. The structure of chitosan is cross-linked by the formation of substituted imine $(-\mathrm{CH}=\mathrm{NR})$ from the chitosan $-\mathrm{NH} 2$ group with an aldehyde group from glutaraldehyde and the resistance of the membrane can be stable in acidic condition (Beppu, et.al, 2007) and ( Hastuti, et.al, 2011).
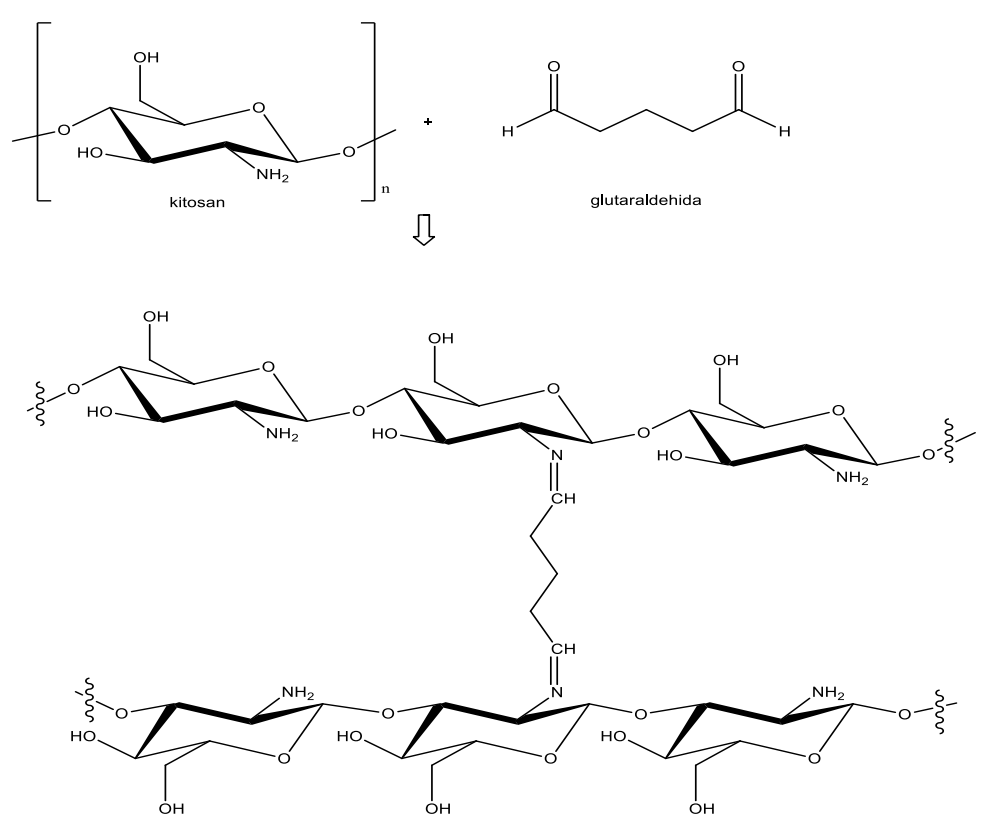

Figure 3. The cross linking of chitosan and glutaraldehyde

\section{Materials and Method}

\subsection{Equipment and Materials}

Pectin was obtained from local pectin derived from orange peel. Chitosan was isolated from crab shells. Sodium hydroxide, acetic acid, distilled water and glutaraldehyde were also used.

The equipments used in this study were glassware, ovens and FTIR spectrophotometers (Prestige-21 Shimadzu).

\subsection{Research Procedure}

The synthesis of chitosan-pectin PEC membrane cross-linked with glutaraldehyde was initiated by dissolving $0.6 \mathrm{~g}$ pectin in $20 \mathrm{ml}$ of distilled water and added with $1.4 \mathrm{~g}$ of chitosan in $78 \mathrm{ml}$ of $0.4 \mathrm{M}$ acetic acid to a homogeneous solution. Then, as much as $2 \mathrm{ml}$ glutaraldehyde $30 \%$ was added and placed in a petri dish and evaporated at the temperature of $70{ }^{\circ} \mathrm{C}$. After that, the membrane releasing process was carried out by adding $1 \mathrm{M} \mathrm{NaOH}$ solution for 12 hours and 
rinsed with distilled water, and then dried at room temperature. Chitosan-pectin PEC membrane cross-linked with glutaraldehyde was varied by membrane composition namely chitosan: pectin with the ratio of 70:30; 80:20; and 90:10 with variations in the concentration of glutaraldehyde 30\%. It is further described in Table 1.

Table 1. The composition variation of PEC membrane

\begin{tabular}{lccc}
\hline $\begin{array}{l}\text { Chitosan: } \\
\text { pectin }\end{array}$ & $\begin{array}{c}\text { Chitosan } \\
(\mathrm{g})\end{array}$ & $\begin{array}{c}\text { Pectin } \\
(\mathrm{g})\end{array}$ & $\begin{array}{c}\text { GLA } \\
(\mathrm{mL})\end{array}$ \\
\hline $70: 30$ & 1.4 & 0.6 & 2 \\
$80: 20$ & 1.6 & 0.4 & 2 \\
$90: 10$ & 1.8 & 0.2 & 2 \\
\hline
\end{tabular}

The characterizations of PEC chitosan-pectin membranes cross-linked with glutaraldehyde were carried out with FTIR spectrophotometer, water uptake with variations of time 30, 120, 240, 360, and 1440 minutes and medium acidity test to determine whether chitosan-PEC membrane pectin is cross linked stable at certain $\mathrm{pH}$ ranging from $1,3,5,7$, and 9.

\section{Result and Discussion}

The membrane produced was then characterized using the FTIR spectroscopy to investigate the interaction between the - $\mathrm{NH} 3$ + group from chitosan and the carboxyl group (-COO-) from the pectin. Also, the ability to absorb water, the acidity test towards the medium were also conducted.

\subsection{FTIR Characterization}

The membrane produced was then characterized using an FTIR spectrophotometer. The FTIR spectra of chitosan-pectin PEC membrane cross-linked with glutaraldehyde can be seen in Figure 4.

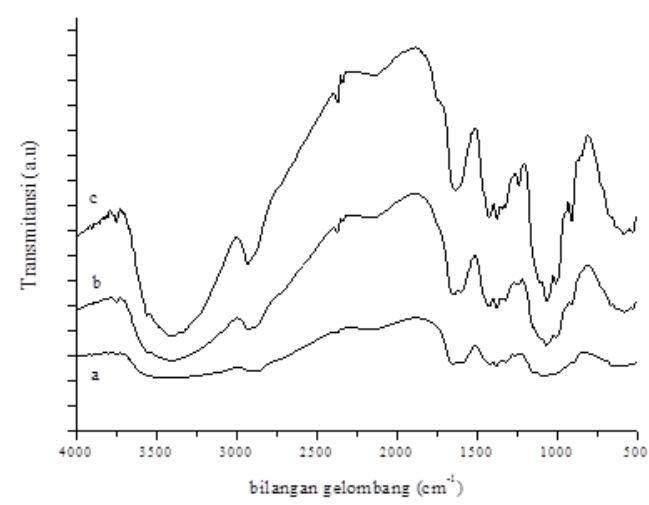

Figure 4. The FTIR spectra of: a. chitosan; b. pectin, c. cross-linked PEC membrane 
Chitosan FTIR spectra (figure 4a) showed that an absorption in the area of $2877.79 \mathrm{~cm}-1$ was stretching vibration of the $\mathrm{C}-\mathrm{H}$ methylene group and absorption in the area of $1080.14 \mathrm{~cm}-1$ indicated the presence of C-O groups. The absorption in the area of $3425.58 \mathrm{~cm}-1$ shows stretching vibrations of the $\mathrm{O}-\mathrm{H}$ group that overlap with $-\mathrm{NH}$ from amines. Moreover, absorption at $1651.07 \mathrm{~cm}-1$ reveals that amide still appears, indicated an acetyl group in the carbon chain and the amount decreases with the deacetylation process (Mourya, et.al, 2010), dan (Auta \& Hameed, 2014).

The FTIR of pectin spectra (figure 4b) indicated absorption at the area of $3387.00 \mathrm{~cm}-1$ which corresponds to the $-\mathrm{OH}$ vibration and at the area of $2939.52 \mathrm{~cm}-1$ was a stretch of the aliphatic $\mathrm{C}-\mathrm{H}$ vibration. The absorption characteristics of pectin are found to be at $1064.71 \mathrm{~cm}-1$ and $1627 \mathrm{~cm}-1$ which shows the existence of stretching vibrations of $-\mathrm{CO}-$ and $-\mathrm{COOH}$ clusters, (Hastuti \& Siswanta, 2013) and (Wang, et.al, 2014).

Lastly, the FTIR spectra for chitosan-pectin PEC membrane cross-linked with glutaraldehyde was displayed by figure 4c. The formation of complex polyelectrolytes is observed at the absorption wavelength of $1604.77 \mathrm{~cm}-1$ which indicates the interaction between the $-\mathrm{NH} 3+$ group from chitosan and the -COO-group- (Leonard \& Hubert, 2006), and (Tahtat et al., 2013).

\subsection{Medium acidity}

The acidity test of the medium was performed to determine the stability of PEC chitosan-pectin membrane cross-linked with glutaraldehyde in various $\mathrm{pH}$ variations. Variations in $\mathrm{pH}$ used were $\mathrm{pH} 1,3,5,7,9$. The resulting membrane was not stable at $\mathrm{pH} 1$ and suffered damage in the 5th minute, this is because a large concentration of $\mathrm{H}+$ can protonate $-\mathrm{NH} 2$ to $-\mathrm{NH} 3+$ while ions of - $\mathrm{COO}$ - are very little in amount and $-\mathrm{COOH}$ is more favorable so that the interaction between chitosan and pectin is difficult to occur.

The chitosan-pectin PEC membrane cross-linked with glutaraldehyde is stable at $\mathrm{pH} 3$ and 5 to 24 hours without any damage occurred. This is due to the number of $\mathrm{H}+$ ions capable of protonating a part of the $-\mathrm{NH} 2$ group to $-\mathrm{NH} 3+$, and some of $-\mathrm{NH} 2$ will cross with glutaraldehyde so the membrane is stable at $\mathrm{pH} 3$ and 5.

Furthermore, the chitosan-pectin PEC membrane cross-linked with glutaraldehyde was stable at pH 7 and 9. This is related to the condition where $-\mathrm{NH} 3+$ was not formed so that the interaction of $-\mathrm{NH} 3+$ with $-\mathrm{COO}-$ is weakened. The crosslinking between chitosan and glutaraldehyde can maintain the membrane structure or not being damaged up to 24 hours. The interactions of chitosan and pectin and cross-linked links of chitosan and glutaraldehyde are shown in Figure 5. 


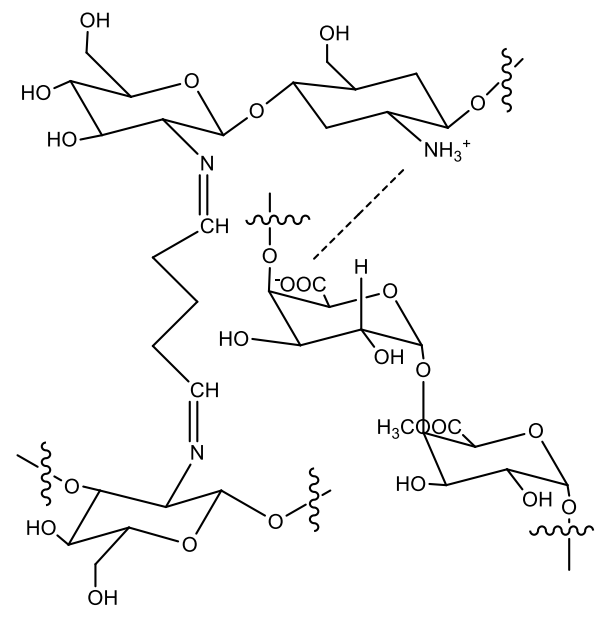

Figure 5. The interaction of chitosan-pectin and cross-linked with glutaraldehyde

\subsection{Water Uptake}

The chitosan-pectin PEC membrane cross-linked with glutarldehyde was then characterized with water uptake method by weighing each membrane dry weight and soaking in sterilized water with a time variation of 30,120, 240, 360 and 1440 minutes. After that, the wet weight of the membrane was balanced to determine the percentage of water uptake. The results showed that the membrane with the chitosan: pectin composition of 70:30 with 30\% glutaraldehyde indicates the maximum ability to absorb water at 30 minutes is $266.67 \%$. This is due to the presence of active groups of pectin, namely carboxylic (-COOH) and hydroxyl (-OH) which are hydrophilic and able to form hydrogen bonds in large amount, while the active group of chitosan (-NH2) has been used to cross links with glutaraldehyde, so that the more composition of pectin in the membrane, the higher the ability to absorb the water. The order of absorption of water from large to small is $70: 30 ; 80: 20$; and $90: 10$ with $30 \%$ glutaraldehyde of $266.67 \%$, $154.44 \%$, and $148.32 \%$ respectively.

This membrane has the ability to absorb water in a small amount. This relates to the active group of chitosan (-NH2) has bind to large amounts of glutaraldehyde and its also used to bind to pectin, so that its shape becomes rigid and its ability to absorb water decreases. The water absorption curve is shown in Figure 6. 


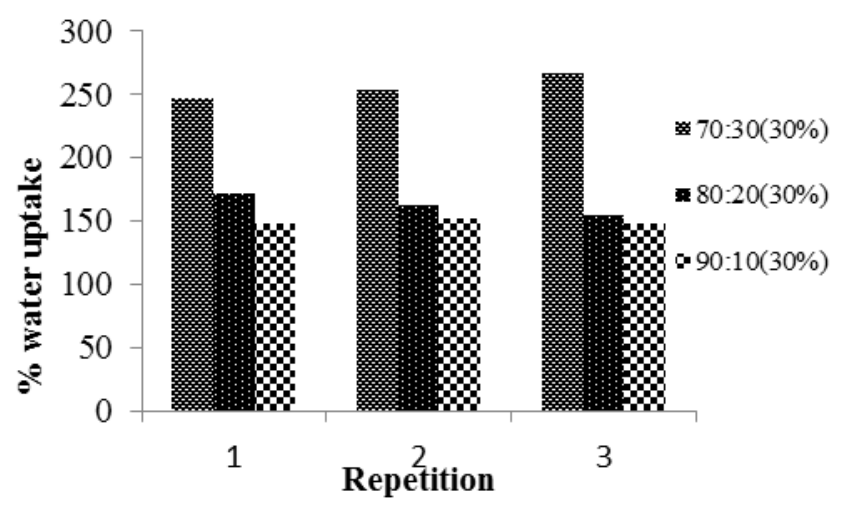

Figure 6. Water uptake

\section{Conclusion}

The chitosan-pectin PEC membrane can be made by mixing chitosan and pectin which interact to form complex polyelectrolytes. The addition of glutaraldehyde aims to cross link chitosan by forming a substituted imine bond, so that the membrane remains stable at $\mathrm{pH}$ below 5 . Based on the $\mathrm{pH}$ resistance test, chitosan-pectin PEC membrane cross-linked with glutaraldehyde is stable at $\mathrm{pH}$ 3. The modification of chitosan with pectin and forming complex polyelectrolyte membrane aims to increase membrane adsorption capacity. Characteristics of chitosan-pectin PEC membranes with FTIR showed an absorption in the area of $1604.77 \mathrm{~cm}-1$. This corresponds to an interaction between $-\mathrm{NH} 3+$ from chitosan and - $\mathrm{COO}$ - from pectin to form complex polyelectrolytes. The chitosan / pectin PEC membrane cross-linked with glutaraldehyde is stable at $\mathrm{pH}$ ranges from 3-9. The maximum water uptake was observed from the chitosan: pectin composition of $70: 30$ with $30 \%$ glutaraldehyde, with the water uptake percentage of $266.67 \%$.

\section{References}

[1] Auta, M., \& Hameed, B. H. (2014). Chitosan-clay composite as highly effective and low-cost adsorbent for batch and fixed-bed adsorption of methylene blue. Journal of Chemical Engineering, 237, 352-361.

[2] Beppu, M. M., Vieira, R. S., Aimoli, C. G., \& Santana, C. C. (2007). Crosslinking of chitosan membranes using glutaraldehyde: Effect on ion permeability and water absorption. Journal of Membrane Science, 301(1-2), 126-130.

[3] Canella, K. M. N.; Garcia, R. B. 2001. Caracterização de Quitosana por Cromatografia de Permeação em Gel - Influência do Método de preparação e do Solvente. Quim. Nova 24, 1, 13:17.

[4] Chatelet, C., Damour, O., Domard, A. 2001. "Influence of the degree of acetylation on some biological properties of chitosan films". Biomaterials, 22, 261- 268. 
[5] Curroto, E. Fresia, A. 1993. Quantitative determination of chitosan and the percent age of free amino groups. Analytical Biochemistry 211: 240-241.

[6] Dee, J.D., Rhode, O., Wachter, R., 2001. " Chitosan-Multi- functional marine polymer" Cosmetics and Toiletries, 116, 2, 39-42.

[7] Gargioni, K., Correa, P., \& Bernusso, L. D. C. (2006). Synthesis and Physicochemical Characterization Chemically Modified Chitosan by Succinic Anhydride. Jorunal Brazil Archives of Biology and Technology, 49(July), 665-668.

[8] Hastuti, B., Masykur, A., \& Fariha, I. (2011). Modiikasi Kitosan Melalui Proses Swelling Dan Crosslinking Menggunakan Glutaraldehit Sebagai Pengadsorpsi Logam Cr ( Vi ) Pada Limbah Industri Batik. Jurnal EKOSAINS, III(3), 14-21.

[9] Hastuti, B., \& Siswanta, D. (2013). The Synthesis of Carboxymethyl Chitosan-Pectin Film as Adsorbent for Lead (II) Metal. International Journal of Chemical Engineering and Applications, 4(6), 349-353.

[10] Herwanto, B. (2006). Adsorpsi Ion Logam Pb ( II ) Pada Membran Selulosa-Khitosan Terikat Silang. Akta Komindo, 2(1), 9-24.

[11] Khan, T. A., PEH, K.K., Ching, H.S.,2002. "Reporting degree of deacetilation values of chitosan: the influence of analytical methods". J.Pharm. Pharmaceut.Sci., 5(3):205212.

[12] Leonard, M., \& Hubert, P. (2006). Physical Alginat Hidrogel based on Hydrophobic or Dual Hydrophobic/ Ionic Interaction: Bead Formation, Structure and Stability. Journal of Colloid and Interface Science, 10(1), 10-16.

[13] Ma, X., Wei, R., Cheng, J., Cai, J., \& Zhou, J. (2011). Synthesis and characterization of pectin/poly (sodium acrylate) hydrogels. Journal of Carbohydrate Polymers, 86(1), 313319.

[14] Marudova, M., MacDougall, A. J., \& Ring, S. G. (2004). Pectin-chitosan interactions and gel formation. Journal of Carbohydrate Research, 339(11), 1933-1939.

[15] Mourya, V. K., Inamdar, N. N., \& Tiwari, A. (2010). Carboxymethyl chitosan and its applications. Advanced Materials Letters, 1(1), 11-33.

[16] Rahmawati, H., \& Iskandar, D. (2014). Sintesis Karboksimetil Kitosan terhadap Pengaruh Konsentrasi Natrium Hidroksida dan Rasio Kitosan dengan Asam Monokloro Asetat. Jurnal Tekno Technscientia, 6(2), 145-155.

[17] Singla, A. K. and Chawla, M. 2001. "Chitosan: some pharmaceutical and biological aspects - an update" J. of Pharmacy and Pharmacology, 53, 1047-1067.

[18] Tahtat, D., Mahlous, M., Benamer, S., Khodja, A. N., Oussedik-Oumehdi, H., \& Laraba-Djebari, F. (2013). Oral delivery of insulin from alginate/chitosan crosslinked by glutaraldehyde. International Journal of Biological Macromolecules, 58, 160-168.

[19] Tanasale, M., Killay, A., \& Laratmase, M. (2012). Kitosan dari Limbah Kulit Kepiting Rajungan (Portunus sanginolentus L.) sebagai Adsorben Zat Warna Biru Metilena. Jurnal Natur Indonesia, 14(2), 165-171.

[20] Wang, X., Chen, Q., \& Lü, X. (2014). Pectin extracted from apple pomace and citrus peel by subcritical water. Food Hydrocolloids, 38, 129-137. 